\title{
Crime, fear and continuous traumatic stress in South Africa: What place social cohesion?
}

\section{[R E F L E C T IO N S ]}

\section{Abstract}

International literature on crime and violence suggests that social cohesion may play a key role in facilitating prevention at community level. It is argued that in South Africa high levels of crime entailing interpersonal violation not only reflect ruptures in the social fabric but also contribute to social disorganization. In exploring the traumatic impact of exposure to fairly pervasive criminality via the constructs of Fear of Crime (FoC) and Continuous Traumatic Stress the article explores some of the linkages between responses to crime and the facilitation or erosion of potentialities for social cohesion. It is argued that the common responses of fearfulness, suspicion and social withdrawal (as well as defensive aggression in some instances) are counter-productive to attempts to build pro-social organization. Consequently a rather intractable circular relationship may ensue in which the conditions that enable criminality are not challenged because indirect and direct exposure to violation, alongside perceived and actual deficits in formal state interventions, have eroded the motivation and capacity of citizens to tackle such conditions, leaving spaces open for violation to continue unchecked, Some of the complexities of thinking about forms of social cohesion as a route to challenge crime and its impact in South Africa are elaborated. It is emphasized that collective efficacy appears to be the aspect of social cohesion that is most pivotal in addressing this feature of society.

\section{Introduction}

Thinking about social cohesion, whatever valence this holds for different citizens in South Africa, seems an

\section{Gillian Eagle}

Department of Psychology, University of the

Witwatersrand, Johannesburg

Gillian.Eagle@wits.ac.za

\section{Keywords:}

social cohesion, crime, fear of crime, continuous traumatic stress, collective efficacy, South Africa 
important project at this time in our history. The post-apartheid state is under pressure and ruptures are evident across a broad range of social formations including the trade unions, political constituencies and civil society groupings, as evidenced, for example, in tensions between national and non-national citizens, pervasive service delivery protests, labour unrest, student demonstrations, racial polarisation, and the range of legal battles taking place in response to allegations of corruption and abuses of power, many of these directed at government figures and agencies. In addition, the South African economy is ailing in many respects, unemployment is severe, and wealth inequality amongst the highest in the world. Such conditions not only reflect a lack of social cohesion but also threaten any project designed to enhance this aspect of social relationship.

Within this article I aim to focus on one aspect of contemporary South African life that arguably contributes in an indirect yet pervasive manner to social mistrust and alienation. It is evident that exposure to high levels of criminality and widespread fear of crime contribute not only to individual and group anxieties and attitudes but also to public discourses that entrench notions of threat and justify intergroup prejudice. There is a considerable body of work, largely sociological, that has sought to explore the relationship between social cohesion, and its inverse, social disorganization, and the prevalence of crime and nature of responses to crime. In this article I seek to examine two related but divergent responses to crime in South Africa, the one, Fear of Crime (FoC), representing a possibly exaggerated response to risk, and the other, Continuous Traumatic Stress (CTS), in many instances associated with the need to minimize or accommodate to the reality of threat in order to survive in inescapably crime ridden environments. FoC and CTS both carry psychological as well as discursive weight and have individual as well as communal effects. They also both reflect responses to the context in which crime takes place as much as to crime itself and in these respects have further implications for thinking about social cohesion. I wish to offer some reflections not only upon how more "symptomatic" or traumatic stress related responses and behaviours might impact on potentialities for social cohesion, but also on how the context of CTS and FoC highlight structural and symbolic features of South African society that are in tension with the generation of social cohesion. As will be elaborated further, CTS reflects not only the likelihood of poly-victimization and multiple trauma exposure, but is revealing of the lack of protection of citizens by those agencies designed to promote human welfare and uphold the rule of law. It has also been found that FoC is related not only to frequency of actual criminal events, but in addition to perceptions concerning levels of social "incivility" and the stability and efficacy of societal regulation mechanisms. Both of these features, i.e., objectively established high crime levels and what they signify for citizens in terms of state and community social controls, seem significant in thinking about social rupture and cohesion in contemporary South Africa. 


\section{Contextualization}

With hindsight some 20 years on, it is evident that despite the great optimism that characterized the immediate post 1994 period in South Africa, many of the same social problems that predated this period have resurfaced or endure. It is interesting that a number of articles published in a variety of news media (Mail \& Guardian, Saturday Star, Sunday Independent, amongst others) during 2015 have revisited the limitations and gains of the Truth and Reconciliation Commission (TRC) with a particular focus on failures in reparation and post-commission prosecutions and have also examined the legacy of the 1976 youth protests in relation to current youth development, concluding that life circumstances continue to be dire for many. Some 25 years ago I coauthored an article on endemic violence against women (Vogelman \& Eagle, 1991) in a special edition of Social Justice devoted to South Africa, in which it was argued that a range of background features of society, including a powerful patriarchal culture, needed to be tackled if gender violence was to be reduced. Currently, despite the instantiation of many highly progressive gender policies, rather than seeing an improvement in gender relations, South Africa manifests extremely high levels of gender violence including rape, intimate partner assault and femicide (Jewkes \& Abrahams, 2002; Jewkes et al, 2006). There are also increasing reports of police brutality and torture that appear to replicate many of the features of the violence of state forces under apartheid. Thus, in many quarters, it appears that those who believed in the project of nation building, redress and social justice have failed to bring about the kind of change we/they ideally envisaged.

Setting aside some of the admittedly important and complex debates about violence and disruption as perhaps necessary in bringing about particular political objectives, it appears that where social cohesion may be significant and useful is in promoting collective resistance against violence that represents abuses of power, be this at individual, group, community or public level. I would suggest that we are struggling to escape a rather perverse set of social patterns in relation to crime and violence, where the impact of high levels of exposure and associated fear, anxiety, anger, aggression and disillusionment, contributes to a breakdown in desirable aspects of social cohesion, creating a context in which further violations continue to take place largely unchecked. Amongst other aspects, what FoC and CTS appear to do is to reflect not only fractures in society but also to demobilize or inhibit the agency of citizens to take part in progressive social movements and action. In this respect there is something of an iterative cycle in the creation of conditions that are conducive to the commission of crime, responses to pervasive victimization or accounts of victimization, and an inability to then come together to build the kind of social bonds that might produce the necessary communitarianism to prevent criminal acts. 
Before proceeding further it may be useful to offer some qualification of employment of terminology as I am mindful of the complexity of defining not only social cohesion but also the term crime, given overlaps in activities that are labeled as criminal but may be viewed by some as constituting legitimate social protest. In this discussion I am referring primarily and somewhat narrowly to crimes against persons of a largely "private" nature (theft, mugging, robbery, assault, murder and attempted murder, rape, etc.). It is interesting to note that Kawachi, Kennedy \& Wilkinson (1999) were able to demonstrate that particular forms of crime across the United States were more likely to be associated with income inequality than others, wealth disparities being particularly strongly associated with violent crime of an interpersonal nature, as opposed to, for example, being associated with property crime: "Violent crimes (homicide, assault, robbery) were consistently associated with relative deprivation (income inequality) and indicators of low social capital." (Kawachi et al, 1999: 719). It is also the case that while resentment and powerlessness tied to income inequality may be directed at those who have accumulated wealth, the expression of violence in actions may well be directed at those in more immediate proximity, such as family and local community members.

With regard to social cohesion, I am aware that several other authors in this special edition have engaged with the ideological and discursive connotations of the term in considerable depth. Although cognisant of the need to remain critical of the construct and how it is deployed, for the purposes of this discussion social cohesion is employed in the manner in which it is commonly understood in the literature on crime and social cohesion. Within this body of work there appears to be considerable agreement that social cohesion encompasses at least two key components, these being social capital and network density. Social capital is in turn defined as "those features of social organization, such as networks, norms of reciprocity and trust in others, that facilitate cooperation between citizens for mutual benefit" (Putnam, 1993, quoted in, Kawachi et al, 1999: 722) and may be assessed in light of "the level of trust among citizens and the density and rate of participation in voluntary associations and local organizations" (ibid). Increasingly models of social cohesion also incorporate the construct of collective efficacy, although this is sometimes viewed as emerging out of social cohesion. In a very comprehensive definition of social cohesion Forrest and Kearns (2011: 2128) propose that, in summary, the term "can emphasize the need for a shared sense of morality and common purpose; aspects of social control and social order; the threat to social solidarity of income and wealth inequalities between people, groups and places; the level of social interaction within communities or families; a sense of belonging to place." Most of the research on crime and FoC is conducted against this kind of definitional backdrop and this is therefore the broadly defined understanding of social cohesion that is drawn upon here. It is evident that social cohesion is a complex and multi-dimensional construct that incorporates notions of human bonds, 
generally trusting relations, communal resources, the exercise of social controls (both informal and formal) and some aspects of social agency. Several of these aspects will be engaged further in subsequent elaboration of material.

\section{Exposure to crime and traumatic stress related responses}

It is commonly assumed that South Africans have high rates of exposure to traumatic events and to a considerable extent this assumption is borne out by research findings, although different areas of the country show different patterns of exposure, including across the same urban area. In a relatively recent study, the Social and Health Survey (SASH), into aspects of mental health across a cross-section of South African adults, it was found that some $75 \%$ of the population reported exposure to a traumatic event, a figure not markedly in excess of that reported in related contexts (Williams et al, 2007). What was striking, however, was the high rate of multiple exposures, with almost fifty percent of the respondents indicating that they had experienced more than one traumatic event, and some individuals reporting as many as seven events. Research conducted into trauma exposure amongst Johannesburg based students at the University of the Witwatersrand over several years confirmed high overall rates of exposure and also high levels of multiple traumatization (Engelbrecht, 2009; Scott, 2012; McClurg, 2014). These students could not be understood to be living in an unusually high violence environment relative to most urban South Africans, indicating that exposure to threatening events may be common for a broad swathe of the South African population. Certainly if one considers indirect exposure in the sense of witnessing violent or traumatic events and hearing these recounted by work colleagues, friends, family, and members of close social networks, exposure to accounts of direct victimization is very high, contributing to widespread awareness of potential threat in a range of environments.

Interestingly although the SASH researchers found evidence of fairly high trauma exposure levels, they found lower than anticipated levels of Posttraumatic Stress Disorder (PTSD) amongst their sample (Williams et al, 2007). In two large scale public surveys it was established that lifetime prevalence of PTSD for Americans is 7.8\% (Kessler et al, 1995), whereas for the South African population it was established to be 2.3\% (Stein el al, 2008), (although it should be noted some smaller scale South African studies have found more elevated levels of PTSD). The SASH researchers proposed that their South African respondents might express their distress somewhat differently from commonly assumed patterns, presenting with higher levels of depression and somatic problems, but also potentially with sub-clinical features of PTSD and what might appear closer to general stress patterns. Williams et al (2007) did find that levels of PTSD and related mental health difficulties increased in accordance with higher levels of exposure to multiple events, as might be anticipated. Both the possible 
sub-clinical manifestations of direct and indirect exposure as well as the responses to multiple and pervasive victimization are of interest in relation to social cohesion.

\section{Fear of crime and social cohesion}

One of the sub-clinical features that may be evident amongst a large proportion of the population is a high level of "fear of crime", a construct predominantly studied by sociologists and criminologists but more recently also theorised to carry psychological meaning and weight (Jackson, 2006). Although Fear of Crime (FoC) is significantly tied to crime statistics and real patterns of exposure, it is also a phenomenon that reflects attitudinal and behavioural responses that stem from perceptions of risk (Jackson, 2006), as outlined previously.

Surveys assessing FoC are based on responses to questions with evident face validity that ask respondents to rate, for example, how safe they feel in their neighbourhood or home, and whether they are likely to move around freely in their environment during the day or at night. Responses to such surveys indicate people's anxiety levels concerning potential exposure to crime and represent the degree to which they are preoccupied with risk and how this may or may not inhibit their ability to operate within their environment. The most recent "Victims of crime survey: 2013/14" (Statistics South Africa, 2014), which includes data on FoC, indicates that there has been an overall increase in anxiety levels over the past several years. It is apparent that a considerable proportion of the South Africans surveyed (four out of ten) perceived that crime had increased during the period 2010 to 2013, key concerns being burglary and home robbery. While patterns varied across contexts, concerns about safety, particularly at night, were marked, with some $65.1 \%$ or nearly two thirds of respondents reporting feeling unsafe after dark (Statistics South Africa, 2014: 2). There was also an indication that about a third of the population surveyed curtailed their movement in open spaces out of fear of criminal victimization. These findings suggest considerable awareness of crime and related constraint of activity in many instances.

It is evident that for many South Africans the negotiation of occupation of both private and public space is mediated by an appreciation of threat of crime or violence (be this entirely valid or not). Such heightened threat perception contributes to often tense or suspicious interchanges between people who interact as strangers, and particularly effects how young black men are perceived, as pointed out in some of the social commentary on the Oscar Pistorius trial, for example. In addition, however, there is also considerable anxiety concerning people who live in one's immediate environment, with $63 \%$ of households believing "that property and violent crime were likely to be committed by people from their own areas" (Statistics South Africa, 2014: 2). What is interesting about this finding is that it suggests that for large numbers of South African

PINS [Psychology in Society] 49.2015|88 
citizens there is a sense of living amongst other people who will potentially violate their rights - danger lies within rather than only outside of one's community.

It is generally accepted amongst those who study FoC that while there is a link between perceptions of risk and high levels of direct and indirect exposure to actual traumatization, FoC carries surplus currency beyond this. Jackson (2006: 946) suggests that "public attitudes towards crime express and gather meaning within a context of judgments, beliefs and values regarding law and order and the social and moral make-up of one's community and society." FoC contributes to high levels of mistrust, suspicion and wary social interactions that work against the building of social cohesion. Jackson (2004: 949) notes that "the actor reacts in a number of different ways to perceiving danger. Fear (dread or anxiety) is one way ...", and other reactions include "... constrained behavior, community or political activism, compensatory defensive actions, and avoidance behaviours including relocation". This kind of social withdrawal in response to crime and $\mathrm{FoC}$ has also been observed in Brazil: "a greater perception of risk and consequently fear, may lead individuals to become reclusive, with negative repercussions for entire communities" (Villarreal \& Silva, 2006: 1729).

Although South Africans live in a country characterised by high levels of crime and interpersonal violence as assessed against international standards, preoccupation with crime and FoC carries significant discursive and political weight beyond what statistics convey. Jackson (2004: 950) writes that "Crime often operates as a symbol, expressing or condensing a number of other issues, conflicts, insecurities, and anxieties regarding one's neighbourhood, its social make-up and status, its place in the world, and the sense that problems from outside were creeping in." While crime disproportionally affects impoverished and marginalised communities there is a pervasive sense amongst middle class, and perhaps, particularly white middle class, citizens that they are the primary targets of and most vulnerable to crime. Such perceptions have contributed to what some have termed a "siege mentality" epitomized in visible home security, restricted access to particular suburbs and employment of private security companies. Similar patterns of response have emerged in Brazil: "Fear of crime has been blamed for a rise in private security guards as well as the flight of affluent Brazilians to gated communities resulting in a rise in income segregation" (Caldeira, cited in Villarreal \& Silva, 2006: 1747).

Although such measures contribute to feelings of security amongst those who can afford them, they are also divisive and alienating to outsiders who have to move through such communities, such as service workers. Community groups such as "neighbourhood watches" and Community Policing Forums (CPFs) may build particular forms of social cohesion, but may equally contribute to a "we and them" mentality that takes the form of suspicion of those who are seen to intrude into such spaces. It has been observed that 
racial profiling and intergroup prejudice can be exacerbated by such initiatives, as has also been described by Eagle, Benn, Fletcher \& Sibisi (2013) in victims' observations of their responses in relation to exposure to violent crime in South Africa. Forrest \& Kearns (2001: 2134) note that "Social cohesion at the neighbourhood level is therefore by no means unambiguously a good thing. It can be about discrimination and exclusion and about a majority imposing its will or value system on a minority." It is thus evident that responsiveness to crime and fear of crime and the forms of social cohesion they may generate are complex in their impacts and may well undermine the broader kinds of social inclusivity and tackling of root causes that is required. As Forrest and Kearns (2001: 2135) suggest in such "defended neighbourhoods" "an inward looking cohesion of people with similar expectations, outlooks, levels of affluence, or anxieties may co-exist uneasily with an exclusion of the world outside." They argue that social cohesion in such contexts is often "bought" rather than authentically "made". Such concerns resonate with observations made about similar dynamics in many neighbourhoods in South Africa.

It seems then that there may be a considerable difference between social cohesion borne out of pro-social communitarian aims as opposed to that bourne out of purely defensive aims. In addition, networking based on prioritization of protections against crime often contributes to vicarious traumatization as opposed to an increased sense of calm and optimism in interactions. In their research conducted in the favelas of Brazil Villarreal and Silva (2006) found that, paradoxically, social cohesion in communities tended to be associated with higher levels of $\mathrm{FoC}$, hypothesizing that this was due to levels of vicarious traumatization based on common and widespread sharing of information about events that had taken place.

It is evident that $\mathrm{FOC}$ is rather pervasive amongst South Africans and that managing the affect (Jackson, 2004) associated with this element of everyday life requires cognitive and behavioural "work" that depletes resources available for other forms of engagement. It is also evident that FoC reflects broader anxieties about levels of interpersonal trust and the efficacy of both informal and state levels of regulation and social controls. While mobilization against crime may bring people together to take collective action, it may also contribute to heightened anxiety and to building a false or exclusionary sense of social cohesion that perpetuates the larger social divides that contribute to the conditions within which crime escalates. However, it is a feature of South African life that cannot be ignored in efforts to build a more inclusive and egalitarian society.

\section{Continuous traumatic stress and social cohesion}

Up until this point the arguments about exposure to crime, traumatization and $\mathrm{FoC}$, have been focused rather broadly on the South African population as a whole. However, it is 
evident that for certain groups of people, such as migrants from other African countries, and those living in particular environments such as the "Flats" townships of the Western Cape, exposure to traumatic events and threat of future victimisation is the norm rather than the exception. For these kinds of populations fear of assault, robbery and violence is realistic and has to be managed as a dimension of daily life. Kaminer, du Plessis, Hardy \& Benjamin (2013), for example, found very high levels of exposure to violence in home, school and community settings for high school age children in Hanover Park with little sense of respite from trauma exposure in any location. The construct of continuous traumatic stress (CTS), designed to capture the lived experience of people faced with the reality of risk of exposure to current and future violence, including endemic criminal violence in some communities, offers a particular lens through which to attempt to unpack how exposure to crime and threat is a feature of society that derails potentialities for social cohesion.

Drawing upon a conceptualization of trauma exposure generated during the height of apartheid repression, but arguably carrying powerful resonance for particular contemporary contexts across the globe, it has been argued that the construct of Continuous Traumatic Stress (CTS) is more apt than that of Post Traumatic Stress in thinking about the experiences of such populations. Elaborating on the construct of CTS, Eagle and Kaminer (2013) propose that although CTS is so closely tied to context that associated responses or symptoms may disappear or remit upon removal from such contexts (see also Diamond, Lipsitz \& Hoffman, 2013; Straker, 2013), living in environments in which there is realistic appreciation of likelihood of current and future exposure to traumatic stimuli produces very high levels of anxiety, hyperarousal and potential for alarm. Unlike as is the case with intimate partner violence, in CTS contexts the source of the danger is unpredictable and unknown. For people living in such high threat environments it becomes difficult to discriminate between appropriate and paranoid responses to situations, contributing to suspicion, caution and mistrust in interpersonal engagements. Related research into Ongoing Traumatic Stress Responses (OTSRs) in Israel (Diamond, Lipsitz \& Hoffman, 2013) has also found increased intergroup prejudice in situations of CTS.

It is suggested that individuals may engage in polarised ways in order to manage existence under such conditions, in most cases "keeping their heads down" and demonstrating social inhibition and withdrawal, but in some instances, most particularly in the case of young men, assuming aggressive, violence threatening identities themselves (Roach: 2013; Weierstall, Hinsberger, Kaminer, Holtzhausen, Madikane \& Elbert, 2013). These kinds of responses to potential threats from the environment are clearly not conducive to the building of social cohesion as people tend to manage in isolation and also to become resigned to such social conditions if they are experienced as inescapable. 
Emmett (2001: 8) argues that South African residents in under-resourced communities have considerable difficulties in mobilizing against crime: "In response to a question about what they did to prevent violence, $15 \%$ of men and $30 \%$ of women respondents in two informal settlements said they 'did nothing because there is nothing we can do'". He indicates that research conducted under the auspices of the Human Sciences Research Council (HSRC) suggests "increasing withdrawal, passivity and powerlessness in the face of crime, particularly in poorer and more crime-ridden areas." (Emmett, 2001:8). Again there is an indication that pervasive crime is likely to erode social cohesion and individual and communal activism.

One of the features of CTS, alluded to previously, is that the context in which violation is anticipated is marked by an absence of social protections. In some instances, as in the Apartheid "State of Emergency" in response to which the construct was originally derived (Straker and the Sanctuaries Counselling Team, 1987), forces of the state itself are implicated in the attacks on citizens. Within contemporary South Africa, for example, there is some evidence to suggest that "illegal immigrants"' may be subject to abuses by those designated to uphold law and order as illustrated in the Mido Macia case for which nine police personnel are currently on trial. However, even when the state is not actively implicated in abuses of power, "it is very often the case that systems designed to create a sense of accountability and to minimize harm to citizens are ineffectual and overstretched, at best, or corrupt and collusive with informal systems of power at worst" (Eagle \& Kaminer, 2013: 93). As Steinberg's (2008) title of his book on policing in South Africa suggests the "Blue Line" is stretched very thin. It is difficult to envisage how communities can attempt to create social cohesion when the social fabric which is designed to provide the scaffolding within which to establish this lacks potency and credibility. One could question, for example, whether vigilantism against those identified as criminals within a community represents some form of social cohesion? However, given the kind of brutality that is enacted in such situations and the potentiality for mis-accusations (reminiscent of past necklacing of impimpis or informers), while such actions may be comprehensible, it is hard to view them as representing the kind of social cohesion that has positive valence for community psychologists and for this special edition. Thus, as with FoC, there are problems with some context-generated responses to crime that reflect the need to think about social cohesion in conjunction with other ethical considerations.

A further dimension that is interesting to think about in relation to CTS and high violence contexts is the degree to which those committing criminal acts are viewed as outsiders or insiders. Although the Statistics South Africa FoC survey highlighted that over sixty percent of South Africans are mistrustful of people in their immediate communities, there is also evidence to suggest that community members may not "turn in" other 
community members to the authorities, not only out of fear of reprisal but also out of a sense of loyalty. As in the favelas of Brazil: "When residents who violate the law are tightly integrated into community social networks other residents may be less willing to intervene against them. Social cohesion may therefore result in a greater tolerance for criminal activity (Browning, Dietz and Feinberg, 2000)." (Villarreal \& Silva, 2006: 1747). Again, the complexity of the relationship between social cohesion and crime and its regulation is highlighted. It should also be noted that the kind of status that accrues to some criminals, such as gang leaders, linked both to hyper-masculinity and the accrual of wealth, can contribute to feelings of envy and admiration as well as to fear and social censure. Evident wealth inequalities and the need for any source of income, whatever its provenance, may also mean that those who indirectly benefit from crime align with those committing crime rather than those who seek to prevent it.

It is evident that living in high crime and violence environments may well produce conditions for CTS and that individuals preoccupied with safety and survival and mistrustful of anyone outside of their immediate social networks are not easily going to be mobilized into taking part in collective action. In addition, it is evident that the social networks and bonds cohering around crime commission and crime prevention are complicated and are also likely to make for uneasy forms of social cohesion and action.

\section{Conclusion}

Based on the discussion thus far it is argued that the South African population in general is widely preoccupied with vulnerability to crime and violence, with a high proportion of citizens managing a not unrealistic sense of threat on a daily basis. This in turn contributes not only to impaired enjoyment and constructive engagement in daily living but also to the thinning and shearing of social bonds. How then does one begin to entertain and create the conditions for a form of social cohesion that contributes to a less crime facilitating and interpersonally abusive society?

There are no self-evident or easily implementable answers to this question. If there were then the large body of researchers, policy makers, governmental agencies and social activists who have engaged with the scourge of violent crime and interactions in post-transition South Africa would have already have developed effective solutions. It is also not entirely useful to revisit the need for some of the broad scale interventions that have been promoted for years, such as tackling patriarchy and reducing wealth inequalities. We should continue to retain these as vital objectives, but it does seem that building social cohesion, in this instance understood as one of the dimensions of society that may serve to counteract criminal violence, associated fear, and the creation of contexts of CTS, will entail both macro and micro level interventions. Communities will only be able to escape the circularity of the likelihood that responses to exposure to 
violence contribute to the conditions that serve to perpetuate such violence by building social networks that can resist such violations in concert.

Social cohesion is to a large extent predicated on social capital and it may be important to think about what new forms of organization could contribute to accumulation of such capital. During the period of resistance politics in apartheid South Africa social capital and social cohesion were in many instances generated out of communal opposition to state repression and systematic structural abuses and the shared vision of building a democratic and just society (Emmett, 2001). At this point in the history of South Africa it is much harder to identify what kinds of anchor points might create the same kind of platform for social cohesion. It does appear that there are nascent indications of civic organization of various kinds such as marches against corruption and xenophobia. Resistance to crime appears to offer a site for communal mobilization if there is recognition of some of the potential pitfalls of initiatives, such as avoiding exclusionary implications and protecting against sectarian and self-interested motivations. Emmett (2001) observes that for crime prevention strategies to work in poorer communities vertical interventions may need to be prioritized in order to facilitate horizontal action. Thus it is important that those social agencies tasked with providing law and order function effectively in order to generate motivation to engage at community level. In this respect the ongoing calls for effective and trustworthy policing and criminal justice interventions are important as capacitation as this level may leverage and enhance community mobilization.

What has emerged from the international research related to crime and social cohesion is that dense social networks in communities may well not be sufficient to produce the forms of social change required to reduce crime and its impact. As Villarreal \& Silva, (2006: 1747) observe "Social networks by themselves are not enough to generate social control and prevent crime" ... but in addition what is required is "a shared sense of trust and willingness to intervene" (ibid). It has been suggested that "individuals who reside in communities where strong relational networks are present tend to experience less crime and feel safer. Specifically, such integrative relational networks tend to increase the probability that residents will use informal means to control disruptive social activity within their neighbourhoods (Bellair, 2000; Freudenburg, 1986); the presence of informal social controls, in turn, results in less crime and increased feelings of public safety." (Gibson, Zhao, Lovrich \& Gaffney, 2002: 538). Informal social controls to complement formal regulation are reliant on an active citizenry who have some sense of agency and capability, very different from the kind of passive, socially withdrawn and fearful population described as affected by FoC and CTS. In this respect I would argue that individual level interventions may well be required in conjunction with family, group and community level interventions. Individual efficacy is important for collective efficacy

PINS [Psychology in Society] 49 • $2015 \mid 94$ 
and collective efficacy may in turn generate some degree of hope of change and shared impact contributing to a greater willingness on the part of individual citizens to become involved in community initiatives.

In relation to resisting the impact of violent crime it is important to understand that it is collective efficacy (as opposed to social cohesion per se) that is central to countering crime and victimization in communities, although the two are clearly linked. Research from the United States of America has established that an "index of collective efficacy was significantly inversely associated with reports of neighborhood violence, violent victimization, as well as homicide rates." (Wilkinson, Kawachi \& Kennedy, 1998: 582). It is suggested that collective efficacy in relation to crime is represented in the cultivation of a shared morality and recognition of personal rights, in willingness to stand together to censure specific behaviours, in looking out for and coming to the aid of fellow members of one's community, and in attempting to generate conditions for optimal education, employment opportunities, leisure activities and sources of self-esteem for everyone, amongst other aspirational goals.

Collective efficacy proved significant in overcoming the repressive force of the apartheid state but needs to be re-invigorated and redirected in contemporary South Africa in response to the kinds of social problems outlined at the outset. Whether collective efficacy in South African communities looks the same at that promoted in the USA and the UK it is likely that some of the same preconditions pertain to generating such efficacy: "the willingness of local residents to intervene for the common good depends in large part on conditions of mutual trust and solidarity among neighbors. Indeed, one is unlikely to intervene in a neighborhood context in which the rules are unclear and people mistrust and fear one another. It follows that socially cohesive neighborhoods will provide the most fertile contexts for the realization of informal social control. In sum, it is the linkage of mutual trust and the willingness to intervene for the common good that defines the neighborhood context of collective efficacy." (Sampson, Raudenbush \& Earls, 1997: 919). Sociopolitical change is reliant on a citizenry that holds others accountable at every level, from immediate neighbourhood to government. In addition, an active citizenry needs to both censure that which violates and to promote that which creates the conditions for an ethical and humane society, in large measure by exposing and tackling links between structural and more closely interpersonal violence. It is towards this form of social cohesion that we need to aim if we are to attempt to address not only the conditions and states of mind stemming from such high levels of criminality in South Africa but also if we wish to seek to alter the kind of climates within which such criminal potentiality is likely to continue to be generated. 


\section{References}

Browning, C R \& Dietz, R D (2004) The paradox of social organization: Networks, collective efficacy, and violent crime in urban neighborhoods. Social Forces, 83(2), 503-534.

Diamond, G M, Lipsitz, J D \& Hoffman, Y (2013) Nonpathological responses to ongoing traumatic stress. Peace and Conflict: Journal of Peace Psychology, 19(2), 100-111.

Eagle G \& Kaminer D (2013) Continuous traumatic stress: Expanding the lexicon of traumatic stress. Peace and Conflict: Journal of Peace Psychology, 19(2), 85-99.

Eagle G, Benn M, Fletcher T \& Sibisi H (2013) Engaging with intergroup prejudice in victims of violent crime/attack. Peace and Conflict: Journal of Peace Psychology, 19(3), 240-252.

Engelbrecht, S (2009) Exposure to violent crime, fear of crime and traumatic stress symptomatology. Unpublished Masters dissertation. Johannesburg: University of the Witwatersrand.

Emmett, T (2001) Social disorganization, social capital and violence prevention in South Africa. Child, Youth and Family Development Research Programme Report. Pretoria: Human Sciences Research Council.

Forrest, R., \& Kearns, A (2001) Social cohesion, social capital and the neighbourhood. Urban studies, 38(12), 2125-2143.

Gibson, C L, Zhao, J, Lovrich, N P \& Gaffney, M J (2002) Social integration, individual perceptions of collective efficacy, and fear of crime in three cities. Justice Quarterly, 19(3), 537-544.

Hirschfield, A \& Bowers, K J (1997) The effect of social cohesion on levels of recorded crime in disadvantaged areas. Urban Studies, 34(8), 1275-1295.

Jackson, J (2004) Experience and expression: Social and cultural significance in the fear of crime. British Journal of Criminology, 44, 946-966.

Jewkes, R \& Abrahams N (2002) The epidemiology of rape and sexual coercion in South Africa: An overview. Social Science and Medicine, 55(7), 1231-1244. 
Jewkes R, Dunkle K, Koss M P, Levin J, Nduna M, Jama N \& Sikweyiya Y (2006) Rape perpetration by young, rural South African men: Prevalence, patterns and risk factors. Social Science and Medicine, 63, 2949-2961.

Kawachi, I, Kennedy, B P \& Wilkinson, R G (1999) Crime: Social disorganization and relative deprivation. Social Science and Medicine, 48(6), 719-731.

Kaminer, D, du Plessis, B, Hardy, A \& Benjamin, A (2013) Exposure to violence across multiple sites among young South African adolescents. Peace and Conflict: Journal of Peace Psychology, 19(2), 112-124.

Kessler R C, Sonnega A, Bromet E, Hughes M \& Nelson C B (1995) Posttraumatic stress disorder in the National Comorbidity Survey. Archives of General Psychiatry, 52(12), 1048-1060.

Mclurg, L (2014) Relationship of dimensions of trauma exposure and related symptoms to fear of crime and appraisal of future risk. Unpublished Masters dissertation. Johannesburg: University of the Witwatersrand.

Roach, C R (2013) Shallow affect, no remorse: The shadow of trauma in the inner city. Peace and Conflict: Journal of Peace Psychology, 19(2), 150-163.

Sampson, R J, Raudenbush, S W \& Earls, F (1997) Neighborhoods and violent crime: A multilevel study of collective efficacy. Science, 277(5328), 918-924.

Scott, N (2012) Coping style, posttraumatic stress symptomatology, and fear of crime, in victims of crime. Unpublished Masters dissertation. Johannesburg: University of the Witwatersrand.

Statistics South Africa (2014) Victims of Crime Survey 2013/2014. Pretoria.

Stein D, Seedat S, Herman A, Moomal H, Heeringa S G, Kessler R C, \& Williams D R (2008) Lifetime prevalence of psychiatric disorders in South Africa. British Journal of Psychiatry, 192, 112-117.

Steinberg, J (2008) Thin blue: The unwritten rules of South African policing. Johannesburg: Jonathan Ball.

Straker, G (2013) Continuous traumatic stress: Personal reflections 25 years on. Peace and Conflict: Journal of Peace Psychology, 19(2), 209-217. 
Straker, G \& the Sanctuaries Counselling Team (1987) The continuous traumatic stress syndrome: The single therapeutic interview. Psychology in society, 8, 48-78.

Villarreal, A \& Silva, B F A (2006) Social cohesion, criminal victimization and perceived risk of crime in Brazilian neighborhoods. Social Forces, 84(3), 1725-1753.

Vogelman L \& Eagle G (1991) Overcoming endemic violence against women in South Africa. Social Justice, 18(1-2), 209-229.

Weierstall, R, Hinsberger, M, Kaminer, D, Holtzhausen, L, Madikane, S \& Elbert, T (2013) Appetitive aggression and adaptation to a violent environment among youth offenders. Peace and Conflict: Journal of Peace Psychology, 19(2), 138-149.

Wilkinson, R G, Kawachi, I \& Kennedy, B. P. (1998). Mortality, the social environment, crime and violence. Sociology of Health and Illness, 20(5), 578-597.

Williams S L, Williams D R, Stein D J, Seedat S, Jackson P B, \& Moomal H (2007). Multiple traumatic events and psychological distress: The South Africa stress and health study. Journal of Traumatic Stress, 20, 845-855. 